\title{
APLICATIVOS PARA TABLETS: FERRAMENTAS PARA O PENSAR
}

\author{
Débora Valletta - PPGIE/UFRGS, dvalletta@uol.com.br
}

Resumo: As ferramentas dos tablets e/ou smartphones são intuitivas e há inúmeros aplicativos (Apps) que podem ser utilizados como recurso didático tecnológico (Valletta, 2016). Diante desse contexto, este artigo buscou investigar qual a percepção dos estudantes do $2^{\circ}$ semestre em Pedagogia em utilizar jogos educacionais, considerando o uso de tecnologias móveis como, os tablets. Do ponto de vista metodológico a pesquisa é de natureza exploratória e abordagem qualitativa. Como instrumentos de coleta de dados, utilizou-se questionário semiestruturado, observação e fonte documental. Percebeu-se que, alguns resultados merecem destaque, a saber: potencialidade dos artefatos, metodologia implementada e, consequentemente, os padrões emergentes desses dois aspectos.

Palavras-chave: Jogos Educacionais, Aprendizagem Ubíqua, Objetos de Aprendizagem, Formação Docente.

\section{APLICATION FOR TABLETS: TOOLS FOR THINKING}

Abstract: The tools of tablets and/or smartphones are intuitive and there are numerous applications (Apps), it can be used as a technological teaching resource (Valletta, 2016). In this context, this paper aims to investigate perceptions of students of the 2nd. semester in Pedagogy in using educational games, considering the use of mobile technologies, as tablets. From a methodological point of view, this research is exploratory and approach nature qualitative. For data collection instruments, we used semi-structured questionnaire, observation and documentary source. It was noticed some results should be highlighted as potential of artifacts, the implemented methodology and therefore the standards these two aspects have emerged in the study.

Keywords: Educational Game, Ubiquitous Learning, Learning Objects, Trainner Teacher.

\section{Introdução}

As possibilidades de utilizar dispositivos móveis no contexto educacional é uma tendência para apoiar o processo de ensino e aprendizagem. De um lado, o relatório da Cetic Kids ${ }^{1}$ de 2014 demonstrou um aumento expressivo de artefatos $^{2}$ móveis (tablets e celulares) quanto à "proporção de crianças/adolescentes, por tipos de equipamentos utilizados para acessar a internet" em relação ao ano de 2013. Ou seja, houve um crescimento percentual de $100 \%$ sobre o total de usuários de 7 a 13 anos de idade que utilizam os tablets para acesso à internet, enquanto que o uso de celulares sob a mesma faixa etária subiu aproximadamente $65 \%$.

Por outro lado, pesquisas apontam sobre os limites e as possibilidades que os professores se deparam em utilizar tecnologias advindas da computação ubíqua ${ }^{3}$ e pervasiva. Moran (2012) destaca que esses tipos de artefatos [tablets e smartphones] desafiam os docentes nas escolas pelas oportunidades e facilidades de interação entre os 
usuários que dispõe destes dispositivos, interação entre os objetos de aprendizagem e, além de outros elementos que (con)vivem no ambiente escolar. Mateus e Brito (2011) enfatizam o uso de tecnologias móveis desde que estejam integradas ao planejamento pedagógico. Real, Tavares e Picetti (2013) desvelam algumas inquietações dos professores no que diz respeito às políticas públicas, investimentos entre outros fatores socioeconômicos, porém, o estudo desvela a parceria entre os docentes e os estudantes em prol da construção do conhecimento. Sob outra perspectiva, o estudo apresentado por Valletta (2015) discute sobre as possíveis contribuições de um ciclo de formação continuada para o desenvolvimento profissional docente considerando o contexto da computação ubíqua em que professores e estudantes utilizaram os tablets e seus Apps como recurso didático tecnológico durante as atividades educativas em diferentes espaços (dentro e fora da escola) - aprendizagem ubíqua ${ }^{4}$.

Por fim, ressalta-se que as tecnologias estão em constante evolução e inovação na sociedade. Principalmente após o advento da Internet, as transformações tecnológicas ao longo das últimas décadas aconteceram de forma veloz, modificando a cultura e, talvez conduzindo a possíveis mudanças na sociedade contemporânea, sem tempo para refletir sobre como os jovens e as crianças usam esses elementos técnicos em seu cotidiano. Lévy (2010, p. 25-26) destaca que a "técnica é produzida dentro de uma cultura, e uma sociedade encontra-se condicionada por suas técnicas. [...] não se trata de avaliar seus 'impactos', mas se situar as irreversibilidades às quais um de seus usos nos levaria $[. .$.$] e de decidir o que fazer dela". Os professores necessitam se apropriar destes$ artefatos e ferramentas tecnológicas para utilizá-los como recurso didático nas escolas. Nesse sentido, Papert (1988, p. 64) é enfático ao afirmar que “[...] na educação, a mudança virá pela utilização de meios técnicos para eliminar a natureza técnica da aprendizagem na Escola." Logo, não é possível desvincular a utilização de tecnologias móveis no contexto educacional e, se faz necessário observar os hábitos e os comportamentos da geração digital nos diversos espaços de convivência - interação e comunicação.

Os diferentes tipos e funcionalidades dos artefatos se utilizados de modo isolado, não garantem a aprendizagem. Gravina e Basso (2012) destacam as possibilidades de se fazer uso de algumas tecnologias na escola para "experimentos de pensamento", que por meio delas [ferramentas e suas técnicas] podem auxiliar o estudante na "exteriorização, a diversificação e a ampliação de pensamentos". Nesse sentido, os pesquisadores afirmam que "o artefato também tem o poder de agir sobre o sujeito, [...] através das mídias digitais [...] que, quando colocadas nas mãos de nossos alunos, podem provocar mudanças na sala de aula" (Gravina; Basso, 2012, p. 13). Tomando a aprendizagem como um processo intrinsecamente ligado à prática docente, buscou-se investigar a percepção dos estudantes do $2^{\circ}$ semestre em Pedagogia ao utilizar o jogo educacional ${ }^{5}$ denominado de LightBot considerando o uso de tecnologias móveis, o tablet. Nesse sentido, buscou-se analisar se esses futuros professores preferem os computadores do tipo fixo ou móvel para realizar as atividades educativas de experimentação; como utilizariam o softwarelapp com as crianças e, os limites e as possibilidades de se empregar esse tipo de mídia com as crianças.

\section{App Lightbot: um jogo educacional}

O jogo educacional LightBot incentiva o raciocínio lógico matemático e possui semelhanças com outros artefatos disponíveis na plataforma Hour of Code e, em apps 
como Kodable, Move the Turtle entre outros. O criterio para a escolha deste aplicativo [LightBot] deu-se devido: custo zero/free; interface gráfica amigável; disponível para plataforma web e tablets e, na versão do idioma em português/Brasil.

O aplicativo LightBot é um jogo educacional que tem como premissa a introdução de programação para as crianças. Os estudantes podem praticar por meio de "experimentos de pensamento" ações com (ou entre) o objeto e o artefato de forma a construir conceitos como, a sequência lógica.

$\mathrm{Na}$ versão web são 10 fases e ao final das etapas o estudante pode receber um certificado virtual. No início do jogo aparecem algumas mensagens com orientações curtas e objetivas para o usuário, de forma a comunicá-lo qual o objetivo na etapa ( 1 a 10), ou seja, o estudante tem que "pensar" para "agir" sobre as ferramentas para "concretizar" o pensamento de forma a contemplar a fase com excelência.

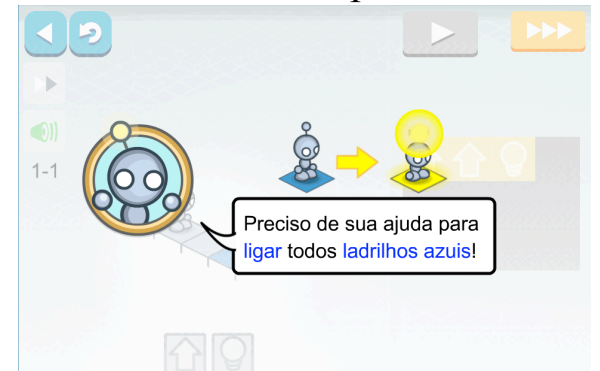

Figura 1 - Orientações emitidas ao estudante

As ferramentas expressas por "botões/ícones" (ir para frente; virar à direita; acender a luz entre outros) auxiliam o usuário a (re)estruturar seu pensamento para mostrar na tela do computador, as ações que foram realizadas pelo sujeito sobre o objeto [aplicativo] e o artefato.

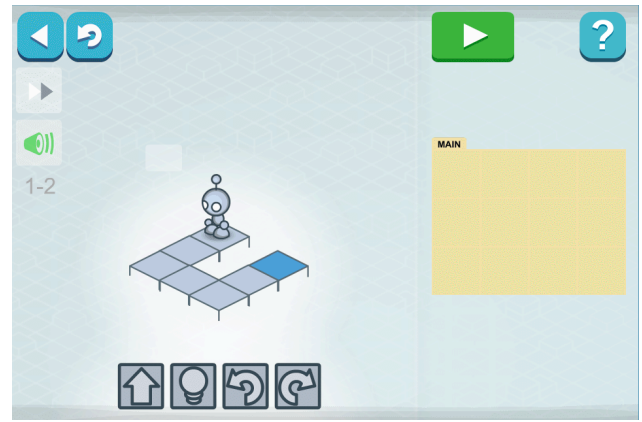

Figura 2 - Diferentes ícones como linguagem não verbal

À medida que o usuário avança nas fases do jogo, as situações-problema, tornam-se mais complexas. Em linhas gerais, é necessário que o usuário: observe os ícones e suas funcionalidades (comandos) para selecioná-los [ícones/comandos] com o objetivo de movimentar o robô para agir de acordo com a sequência lógica escolhida pelo jogador. Logo, é imprescindível resolver situações-problema ao longo dos desafios propostos pelo aplicativo como, passar pelo ladrilho azul e acender a lâmpada/luz.

Ao realizar as ações de cada etapa o sujeito se apropria das ferramentas e, compreende o pensamento lógico associado aos movimentos de interação entre o objeto e o artefato. Assim, os usuários "podem ganhar prática e entendimento dos conceitos básicos de controle de fluxo, testando interativamente sequências de comandos e verificando as consequências na movimentação do robô" (Falcão; Barbosa, 2015, p. 422) propiciando o pensamento computacional por meio de uma exploração no aplicativo. 
Gouws (2013) destaca que sob o ponto de vista da abstração o app LightBot utiliza as funções dos blocos para que os estudantes possam construir um pensamento no início e no final de cada fase do jogo.

É possível considerar este percurso de "tomada de consciência" nos estudos de Becker (1999, p. 3) sob a perspectiva de Piaget que:

No trajeto da ação, cujo percurso vai transformando objeto e sujeito, pode ser visto como tomada de consciência: a partir dos resultados da ação o sujeito vai se apropriando, progressivamente, dos mecanismos íntimos da ação pró-pria. De uma forma mais simples, podemos dizer que o sujeito vai-se dando conta, por força de sua crescente capacidade representativa, de como ele age, tomando-se capaz de reproduzir sua ação corrigindo seus rumos, eliminando trajetos desnecessários ou criando trajetos novos, dirigindo-a para novos objetivos, etc.

Segundo essa abordagem, infere-se que, a arquitetura da informação dos desafios inseridos no aplicativo por meio dos "blocos e suas funções", possibilita ao usuário interagir com o objeto de aprendizagem de forma dinâmica e atraente.

\section{Percurso metodológico}

Participaram desta pesquisa sete estudantes que cursavam o $2^{\circ}$ semestre de Pedagogia. Utilizou-se como instrumento para coleta de dados um questionário semiestruturado, observação e fonte documental. Os participantes aceitaram o Termo de Consentimento Livre e Esclarecido (TCLE) ao acessarem o link do instrumento e clicarem no item denominado "Aceito participar desta pesquisa", o qual foi disponibilizado no ambiente Moodle ${ }^{6}$. Os dados foram examinados a partir da análise textual discursiva de Moraes e Galiazzi (2011), tendo como fundamentação teórica: gênese Instrumental profissional de Tecnologias Digitais da Informação e Comunicação (TDIC) de Abar e Alencar (2013) sob a perspectiva de Rabardel (1995), a metodologia para seleção de aplicativos de Valletta (2014) entre outros autores.

Para facilitar a apresentação no texto e garantir o anonimato dos entrevistados, utilizou-se a letra $\mathrm{S}$ seguida do número que representa diferentes sujeitos.

$\mathrm{Na}$ análise final foram interpretadas as categorias empíricas dialogando com os teóricos consultados, com o conhecimento dos pesquisadores, num movimento dialético para a articulação de um dos desafios da contemporaneidade, o uso de tecnologias móveis, a fim de promover discussões pertinentes ao uso de um recurso didático tecnológico para auxiliar no desenvolvimento de atividades educativas para o raciocínio lógico matemático.

\section{0 diálogo entre professor, estudantes e objeto: ferramenta para o pensar}

No início da disciplina Tecnologias da Informação e Comunicação em Educação I, os estudantes do curso de Pedagogia acessaram o jogo educacional, LightBot, nos computadores de mesa (desktops) do laboratório de informática - espaço em que fora ministrada a disciplina no decorrer do semestre.

A disciplina decorreu no $2^{\circ}$ semestre de 2015 , com três horas semanais cada e se desenvolveu com uma turma de 11 estudantes. O trabalho com esse aplicativo foi proposto para introduzir o uso de jogos educacionais matemáticos no planejamento escolar. Para tal, cada estudante utilizou um computador de mesa e, acessou o link 
informado pela professora. Para cada questionamento ou dúvida, a docente dialogava com os estudantes por meio de uma nova pergunta ${ }^{7}$ propiciando que eles [estudantes] pudessem pensar e interagir com o artefato e o objeto de aprendizagem. Além de, fomentar o trabalho em equipe - habilidades socioemocionais ${ }^{8}$.

A oportunidade que os estudantes tiveram para explorar as ferramentas no artefato do tipo, computadores de mesa, serviu para evidenciar que apesar de nunca terem jogado o aplicativo LightBot a interface intuitiva permitiu que eles pudessem manipular o objeto sem que o professor tivesse que ensiná-los a usar o artefato para obter o desempenho necessário e passar para a próxima fase/etapa. Cabe destacar que na fase inicial notou-se que parte dos estudantes que observou a interação dos colegas entre o objeto e o artefato voltava para os seus respectivos computadores e conseguia jogar sem a necessidade de qualquer tipo de ajuda por parte do docente.

O desenvolvimento subsequente da aula pareceu indicar que a estratégia utilizada obteve êxito, uma vez que foi construída uma atividade sobre o que representa trabalhar com artefatos que possam dar sentido e significado para o futuro professor, de como estimular "o pensar". Nesse sentido, os participantes relataram os limites e possibilidades de se utilizar o aplicativo na escola sem que o docente "ensine-os" a usar as ferramentas.

S1: "É preciso ter paciência para jogar esse aplicativo! Antes de criar o comando é preciso analisar e prever o comando no aplicativo, assim não se comete erro e nem se perde tempo criando novos comandos! É preciso utilizar o raciocínio lógico".

S2: "O jogo possibilita interação entre colegas, raciocínio, pensamentos, técnicas e paciência. Estimula o pensamento e o raciocínio e traz benefícios até para a coordenação".

S5: "Usar o aplicativo em aulas de informática, aulas para desenvolverem a lógica e o raciocínio".

S6: "Enquanto a atividade estiver sendo feita acredito que esteja dentro do contexto escola. E, este sim, a possibilidade de uso em sala. Porque se trabalha com lateralidade".

Por outro lado, pode-se perceber que no comentário de S1 que, para materializar os movimentos do robô na tela do computador houve a necessidade de diferentes operações mentais - habilidades cognitivas.

- Observar o significado de cada ícone;

- Compreender a sequência dos movimentos a serem realizados no percurso pelo robô;

- Analisar os movimentos do robô para completar o percurso com êxito;

- Aplicar os ícones no ambiente para a movimentação do robô;

- Avaliar os movimentos do robô;

- Testar o percurso do robô.

Quanto à resposta de S6 observou-se que durante a atividade o estudante estava com dificuldades entre selecionar o ícone de movimento para esquerda e/ou direita.

Dos sete estudantes que responderam ao instrumento, dois haviam utilizado algum tipo de jogo educativo com as crianças, pois trabalharam em projetos sociais que faziam uso dos laboratórios de informática em suas respectivas instituições de trabalho. 
Para finalizar a atividade prática voltada ao planejamento de jogos educacionais foi entregue um tablet (sistema operacional iOS - Apple) para os estudantes jogarem o mesmo aplicativo - experimentação com outro tipo de artefato. Nessa experimentação, os estudantes encontraram maior facilidade em utilizar as ferramentas tanto devido à oportunidade anterior de compreender a técnica ${ }^{9}$ como a ação deslizante dos dedos na tela do tablet - tela sensível ao toque dos dedos ou caneta específica. Nesse sentido, tal ação, é desvelada pelos sujeitos a transformação do artefato (1) em instrumento (2). Para Rabardel citado por Abar e Alencar (2013, p. 353) "O instrumento como artefato é constituído no(s) uso(s) que o sujeito faz dele". Logo, os sujeitos se apropriaram dos esquemas pré-existentes a partir das expectativas de aprendizagem para o uso desse tipo de mídia e iniciaram o esboço de uma possível atividade educativa - planejamento pedagógico para o uso da ferramenta.

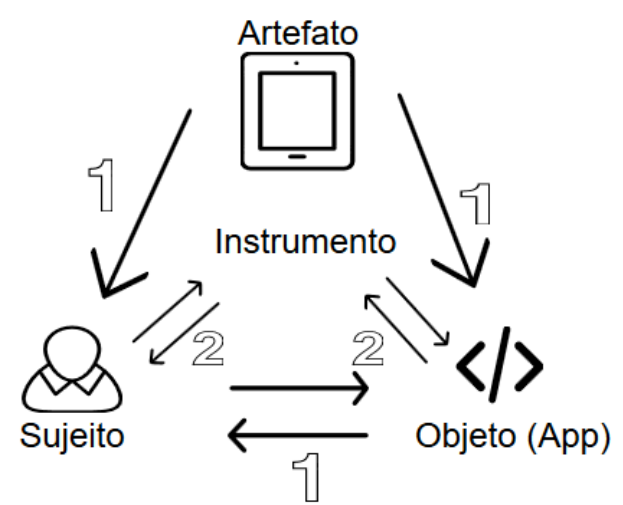

Figura 3 - Modelo da prática experimental

Fonte: Adaptado de Abar e Alencar (2013) sob a perspectiva de Rabardel.

Após todos os estudantes terem explorado as ferramentas, os próprios elaboraram o plano de ensino para a organização de um futuro trabalho pedagógico com as crianças. Foram discutidas as estratégias utilizadas por cada um deles [estudantes] e, como utilizariam o app LightBot com as crianças. Logo, os estudantes apresentaram as suas percepções, a partir de diferentes perspectivas de organização/operação mental, conforme se pode observar nos seguintes depoimentos com grifos da pesquisadora:

S1: "Eu utilizaria esses jogos antes de dar alguma atividade de matemática, pois com esse aplicativo o aluno treina o raciocínio, nas primeiras vezes parece um pouco complicado, mas depois acabamos pegando o jeito. Particularmente antes de ensinar a tabuada".

S2: "Usaria com os computadores, talvez em grupo, pois um poderia ajudar o colega a resolver o jogo. explicaria como joga (site, funções, setas, objetivos etc) e após eles jogariam, comigo a disposição e de olho no que estariam fazendo...".

S3: "em forma de aula para uma gincana de raciocínio rápido tipo competição".

S4: "em equipe, para a interação".

S5: "Em uma aula onde explicaria de um jeito divertido, usando esses aplicativos, como são programados os jogos de hoje em dia e o que existe por trás dos jogos que temos todos prontinhos na tela do nosso computador".

S6: "Planejaria uma aula de lateralidade espacial. Porque percebo que é muito importante para o conhecimento do aluno". 
S7: "Certamente usaria para trabalhar no momento pedagógico, buscando criar nas crianças soluções para o jogo. Até mesmo trabalhando com eles a dimensão da paciência, estratégia, espírito de grupo e, sobretudo atenção em todos".

As experimentações mostraram diferentes tentativas dos sujeitos em utilizar os artefatos com sentido e significado para o planejamento pedagógico como, o raciocínio lógico. Por outro lado, os estudantes de Pedagogia têm diferentes percepções para utilizar os jogos educacionais em sala de aula. Foram experiências pontuais, realizadas de maneira sistematizada.

Nota-se que os estudantes S1, S3 e S7 conseguiram apropriar-se dos artefatos e o transformaram em instrumento - nível 2 (Figura 2). Contudo, os sujeitos S2 e S5 estavam no nível de apropriação técnica do artefato para o uso pedagógico - nível 1 (Figura 1). Por fim, o S4, talvez, esteja no primeiro nível, uma vez que aparenta ter a preocupação com a interação entre as crianças - as habilidades socioemocionais. Ou seja, o artefato é um meio para promover essas interações como, cooperar no sentido de ajudar os colegas que apresentam maiores dificuldades na execução das mesmas ações problemas em comum. Nesse sentido, Bona e outros autores. (2012, p. 5) sob a perspectiva piagentiana desvelam que a:

[...] cooperação consiste em um sistema de operações, de tal modo que as atividades do sujeito se exercendo sobre os objetos, e as atividades do sujeito agindo sobre outros sujeitos se reduzem, na realidade, a um único sistema de conjunto, no qual o aspecto social e o aspecto lógico são indissociáveis, tanto na forma como no conteúdo.

Assim, identificou-se nesse experimento elementos que favorecem o uso de tecnologias móveis, tais como: a mobilidade e a tela sensível ao toque.

A maneira como os estudantes realizaram as ações entre objeto e instrumento proporcionou-lhes oportunidades, na medida em que exploravam as ferramentas e compartilharam significados para o uso do artefato por meio do diálogo entre os colegas. Na prática, os estudantes precisaram testar hipóteses sob qual objeto selecionar para obter certo movimento e, inversamente, qual o desempenho do robô ao aplicar o objeto na plataforma. Desse processo emergiram outros conceitos matemáticos relacionados ao tempo e espaço, como: orientação, direção, sentido entre outros.

Sob a perspectiva de Lévy (2010, p. 21) as verdadeiras relações entre a tecnologia e a cultura, estão "entre um grande número de atores humanos que inventam, produzem, utilizam e interpretam de diferentes formas as técnicas". De fato, o "artefato também tem o poder de agir sobre o sujeito [...] com os quais os alunos podem fazer muitos experimentos de pensamento!" (Gravina; Basso, 2012, p. 13). Logo, os estudantes puderam utilizar "ferramentas para o pensamento" com uma mesma interface gráfica tanto nos computadores de mesa quanto nos tablets.

Quanto às falas dos sujeitos S2 e S5 desvela-se que, esses futuros professores precisarão passar por outras situações de aprendizagem para que possam assimilar por meio de esquemas mentais anteriores e, que possam provocá-los a construção de novos esquemas a partir do uso de outros tipos de artefatos (aplicativos). Tais situaçõesproblema poderão, talvez, auxiliar no desenvolvimento de competências essenciais para o professor do século XXI rumo à transformação de uma "educação bancária" para uma "educação problematizadora".

Os termos em destaque remetem ao sentido que Becker (2011, p. 281) afirma em sua obra $O$ Caminho da Aprendizagem em Jean Piaget e Paulo Freire, o autor é enfático ao associar a teoria de Piaget sob a luz das ideias de Freire, "[...] o melhor uso 
que este poderia imaginar: [...], pela ação à tomada de consciência, mediante inumeráveis abstrações reflexionantes, transformá-la num instrumento de libertação da opressão ou de construção da liberdade" - humanizar o homem na ação consciente. Logo, observa-se a importância do papel da escola para o exercício da cidadania digital - ampliar diferentes formas de aprendizagem como aquelas advindas e propiciadas pela computação ubíqua.

Por outro lado é importante que os professores possam desenvolver competências para que as crianças sejam contempladas com os benefícios que esses artefatos podem desencadear no processo de aprendizagem (Papert, 1988).

\section{Considerações Finais e Trabalhos Futuros}

Os artefatos estão em crescentes mudanças na sociedade. Algumas explicações para tal aumento estão na facilidade de uso, mobilidade (dispositivos móveis) e diversidade de Apps free ou baixo custo com potencial pedagógico para o uso no contexto educacional (Valletta, 2016). Para Prensky (2011) as crianças e os jovens são nativas digitais, ou seja, nasceram num período em que as tecnologias estão presentes no cotidiano - facilitando inclusive as interações sociais. Por outro lado, Papert (1988) enfatiza a importância do papel da escola para o uso dos computadores. Os professores poderão mudar a cultura atual dos laboratórios de informática quando "entenderem o processo de mudança na Escola [a partir das] ideias que foram bem-sucedidas na compreensão da mudança em crianças" (Papert, 1988, p. 52).

No início do trabalho com o app LightBot, os estudantes, ainda não tinham conhecimento de artefatos que, pudessem auxiliar no pensamento computacional na perspectiva de desenvolver projetos educacionais para o raciocínio lógico. Como "materializar" um "pensamento"? Sem a compreensão dessas relações [sujeito, artefato e objeto] por meio da troca de diálogos constantes articulado pela professora e, o que representava em termos de uma ação "intencional", para favorecer o "aprender a pensar", parte deles [dos estudantes], talvez, não tivera percebido as potencialidades e possibilidades do uso de jogos educacionais como "ferramentas para o pensar". Além disso, Papert (1988) destaca a comunicação como um diálogo importante no uso de computadores - momento para "trocar ideias".

Em estudos futuros pretende-se investigar se os analistas de tecnologias educacionais que atuam em escolas de educação básica auxiliam o professor pedagogo (em exercício) de forma colaborativa ou cooperativa nas articulações pedagógicas de apoio ao docente para o uso de "ferramentas para o pensar". Além de, pesquisas envolvendo estudantes e professores das áreas de Computação e Engenharias.

Por fim, a metodologia para seleção de apps/software proposta por Valletta (2014) e a prática discente (futuros pedagogos) a partir da experimentação, talvez, poderão contribuir na formação pedagógica de um professor que possa estabelecer essas relações matemáticas, com vistas aos artefatos advindos da computação ubíqua e pervasiva, de modo a surgir de modo natural ${ }^{10}$, a aprendizagem ubíqua.

\section{Notas}

${ }^{1}$ TIC KIDS ONLINE. Indicadores. Cetic - Portal de dados, 2014. Disponível em: $<$ http://data.cetic.br/cetic/explore?idPesquisa=TIC_KIDS $>$. Acesso em: 7set. 2016.

${ }^{2} \mathrm{O}$ termo artefato, neste trabalho, refere-se aos computadores, softwares e/ou aplicativos.

${ }^{3}$ O paradigma da ubiquidade foi cunhado por Mark Weiser no final do século XX. Ver discussão em: WEISER, Mark. The Computer for the 21 st Century. Scientific American Ubicomp Paper after Sci 
Am editing. Disponível em: <https://www.ics.uci.edu/ corps/phaseii/Weiser-Computer21stCenturySciAm.pdf>. Acesso em: 7 set. 2016.

${ }^{4}$ Ver discussão em: VALLETTA, Débora. Desenvolvimento profissional docente no contexto da aprendizagem ubíqua: um modelo para o ciclo de formação continuada. Rio Grande do Sul: PUCRS, 2015, 109p. Dissertação de Mestrado.

5 Sob a perspectiva de Bittencourt e Giraffa (2003) os jogos educacionais podem ser utilizados como "ambientes para resolução de problemas" a partir da sequência de interações entre o objeto e o sujeito.

${ }^{6} \mathrm{O}$ Moodle foi o ambiente virtual utilizado durante a disciplina para organizar os conteúdos.

${ }^{7}$ Em uma das questões a professora perguntou ao estudante S6: Quais são as ações que você realiza até chegar a porta?

${ }^{8}$ Ver discussão em: COMPETÊNCIAS SOCIOEMOCIONAIS: material de discussão. Instituto Ayrton Senna, UNESCO, UniTwin: São Paulo, 2014. Disponível em: <http://educacaosec21.org.br/wpcontent/uploads/2013/07/COMPET\%C3\%8ANCIAS-SOCIOEMOCIONAIS_MATERIAL-DE-

DISCUSS\%C3\%83O_IAS_v2.pdf $>$. Acesso em: 20 ago. 2016.

${ }^{9}$ Sob a perspectiva de Lévy (2010).

${ }^{10}$ Refere-se ao que Papert (1988) desvela quando compara a aprendizagem no campo da Medicina sendo como "técnica" enquanto que na escola a aprendizagem é "algo natural".

\section{REFERÊNCIAS BIBLIOGRÁFICAS}

ABAR, Celina Aparecida Almeida Pereira; ALENCAR, Sérgio Vicente. A Gênese Instrumental na Interação com o GeoGebra: uma proposta para a formação continuada de professores de Matemática. Bolema, Rio Claro/SP, v. 27, n. 46, p. 349-365, ago. 2013. Disponível em: $<$ http://www.scielo.br/pdf/bolema/v27n46/v27n46a02.pdf >. Acesso em: 7 set. 2016.

BECKER, Fernando. O sujeito do conhecimento: contribuições da epistemologia genética. Educação \& Realidade, v. 24, n. 1, p. 73-88, 1999.

BITTENCOURT, João Ricardo; GIRAFFA, Lucia Maria. Modelando Ambientes de Aprendizagem Virtuais utilizando Role-Playing Games. In: Simpósio Brasileiro de Informática na Educação, 14., 2003, Rio de Janeiro. Anais. Rio de Janeiro: Comissão Especial de Informática na Educação da Sociedade Brasileira de Computação, Núcleo de Computação Eletrônica, 2003, p. 683-692. Disponível em: <http://www.brie.org/pub/index.php/sbie/article/view/299/285>. Acesso em: 25 ago. 2016.

BONA, Aline Silva; MORAIS, Anuar Daian de; BASSO, Marcus Vinicius de Azevedo; FAGUNDES, Léa da Cruz. Cultura Digital e Aprendizagem Cooperativa. RENOTE - Revista Novas Tecnologias na Educação, Rio Grande do Sul, v. 10, n. 1, p. 1-10, 2012. Disponível em: $<$ http://www.seer.ufrgs.br/renote/article/view/30873/0>. Acesso em: 10 set. 2016.

COMPETÊNCIAS SOCIOEMOCIONAIS: material de discussão. Instituto Ayrton Senna, UNESCO, UniTwin: São Paulo, 2014. Disponível em: <http://educacaosec21.org.br/wpcontent/uploads/2013/07/COMPET\%C3\%8ANCIAS-SOCIOEMOCIONAIS_MATERIAL-DEDISCUSS\%C3\%83O_IAS_v2.pdf $>$. Acesso em: 20 ago. 2016.

FALCÃO, Taciana Pontual; BARBOSA, Rafael. "Aperta o Play!” Análise da Interação Exploratória em um Jogo Baseado em Pensamento Computacional. In: Simpósio Brasileiro de Informática na Educação, 26., 2015, Alagoas. Anais. Alagoas: Comissão Especial de Informática na Educação da Sociedade Brasileira de Computação, 2015, p. 419-428. Disponível em: <http://br-ie.org/pub/index.php/sbie/article/view/5284/3659>. Acesso em: 10 set. 2016.

GRAVINA, Maria Alice; BASSO, Marcus Vinicius de Azevedo. Mídias Digitais na Educação Matemática. In: GRAVIANA, Maria Alice et al. (Orgs). Matemática, Mídias Digitais e Didática: tripé para formação de professores de Matemática. Porto Alegre: Evangraf, 2012, p. 
11-36.

Disponível

em:

$<$ http://www.ufrgs.br/espmat/livros/livro_matematica_midias_didatica_completo.pdf $>$. Acesso em: 10 set. 2016.

GOUWS, Lindsey Ann. The role of computacional thinking in introductory computer science. Grahamstown: South Africa, December 2013. Disponível em: $<$ http://contentpro.seals.ac.za/iii/cpro/app?id=2326548241165375\&itemId=1011152\&lang=eng $\&$ service $=$ blob\&suite $=$ def $>$. Acesso em: 7 set. 2016.

LÉVY, Pierre. Cibercultura. Tradução de Carlos Irineu da Costa. 3ed. São Paulo: Editora 34, 2010. $272 \mathrm{p}$.

MATEUS, Marlon de Campos; BRITO, Gláucia da Silva. Celulares, Smartphones e Tablets na sala de aula: complicações ou contribuições?. In: Congresso Nacional Em Educação EDUCERE, 10., Curitiba. Anais Curitiba, 2011, p. 9.515-9.524. Disponível em: $<$ http://educere.bruc.com.br/CD2011/pdf/5943 3667.pdf $>$. Acesso em: 10 set. 2016.

MORAN, José Manuel. Tablets e netbooks na educação. Acedido em Fevereiro, v. 2, 2012. Disponível em: $<$ http://www.eca.usp.br/prof/moran/site/textos/tecnologias_eduacacao/tablets.pdf $>$. Acesso em: 10 set. 2016.

PAPERT, Seymour. A máquina das crianças: repensando a escola na era da informática. Tradução de Sandra Costa. Porto Alegre: Artes Médicas, 1988.

PRENSKY, M. Digital natives, digital immigrants Part 1. On the Horizon, v. 9, n. 5, p. 1- 6, 2001.

REAL, Luciane M. Corte; TAVARES, Mara Noble Rosane; PICETTI, Jaqueline dos Santos. Formação de Professores para o Uso Educacional de Tablets no Ensino Médio: possíveis mudanças na prática pedagógica. In: Congresso Brasileiro de Informática na Educação, 2 ., Campinas, Anais dos Workshops. Campinas, 2013, p. 657-666. Disponível em: <http://brie.org/pub/index.php/wcbie/article/view/2729>. Acesso em: 10 set. 2016.

TIC KIDS ONLINE. Indicadores. Cetic - Portal de dados, 2014. Disponível em: $<$ http://data.cetic.br/cetic/explore?idPesquisa=TIC_KIDS $>$. Acesso em: 7set. 2016.

VALLETTA, Débora. Gui@ de aplicativos para educação básica: uma investigação associada ao uso de tablets. Encontro Nacional de Didática e Prática de Ensino - ENDIPE, 17. Fortaleza, Anais. Fortaleza, 2014, v. 1., p. 2537-2548.

Desenvolvimento profissional docente no contexto da aprendizagem ubíqua: um modelo para o ciclo de formação continuada. Rio Grande do Sul: PUCRS, 2015, 109p. Dissertação de Mestrado.

Aplic@tivos como recurso didático tecnológico: reflexões para a formação e prática docente. In: Encontro Nacional de Didática e Prática de Ensino - ENDIPE, 18., Cuiabá. Anais, Cuiabá: CRV Editora, 2016, v. 1, p. 1-12. [no prelo].

WEISER, Mark. The Computer for the 21st Century. Scientific American Ubicomp Paper after Sci Am editing. Disponível em: <https://www.ics.uci.edu/ corps/phaseii/WeiserComputer21stCentury-SciAm.pdf>. Acesso em: 7 set. 2016. 